\title{
Therapeutic Options in Unresectable Oral Squamous Cell Carcinoma: A Systematic Review
}

\author{
Meisser Madera (1D) \\ Lesbia Tirado Amador (D) $^{2}$ \\ Carlos Leal Acosta (iD ${ }^{3}$ \\ 'Department of Research, Faculty of \\ Dentistry at the University of Cartagena, \\ Cartagena, Colombia; ${ }^{2}$ Department of \\ Research, Faculty of Dentistry at the \\ Universidad del Sinú, Cartagena, \\ Colombia; ${ }^{3}$ Department of Research, \\ Faculty of Dentistry at the Corporación \\ Universitaria Rafael Nuñez, Cartagena, \\ Colombia
}

\begin{abstract}
Purpose: This review describes the current scientific evidence of therapeutic options in unresectable oral squamous cell carcinoma.

Methods: This study followed the Preferred Reporting Items for Systematic Reviews and Meta-Analyses (PRISMA). We searched MEDLINE (Via PubMed) to identify studies assessing treatments for unresectable oral squamous cell carcinoma. The methodological quality assessment of the included studies was performed using the Joanna Briggs Institute (JBI) checklist tool. The evidence was organized and presented using tables and narrative synthesis.

Results: Thirty-three studies met the eligibility criteria. Most studies had an observational design. The sample size varied from 16 to 916 participants. The methodology quality of the included studies ranged from 2.5 to 10 using the JBI tool. Overall, the optimal treatment of patients with unresectable oral cancer is challenging, so there is a sprinkling of studies assessing a variety of therapeutic options, such as radiotherapy, chemotherapy, concurrent chemoradiotherapy, immunotherapy, targeted therapy plus chemotherapy or radiotherapy, and gene therapy plus chemotherapy.

Conclusion: There is lacking evidence about the benefits of some therapeutic options for unresectable oral squamous cell carcinoma. Overall, these patients can be treated using a multimodal approach such as concurrent chemoradiotherapy or induction chemotherapy followed by chemoradiotherapy, which have shown good clinical outcomes. However, other options could be considered depending on the assessment of risk/benefits, tumor extension, and patient values and preferences.
\end{abstract}

Keywords: mouth neoplasms, unresectable oral cancer, oral squamous cell carcinoma, treatment, therapy

\section{Introduction}

Oral cancer is a health issue globally. It fully meets the criteria to be considered a public health problem such as high mortality rate, the impact of the condition on an individual level, and impact on wider society. ${ }^{1}$ To illustrate, it has been reported that around 650,000 new cases are diagnosed annually; although it represents just $2 \%$ of the tumor incidence worldwide, the major reason for concern is its high mortality rate of around $50 \%{ }^{2}$ Regarding the region-specific incidence age-standardized rates by sex for oral cancer in 2018, there is a higher incidence of this oral disease for men than women in all countries, being Melanesia, South Central Asia, Australia/New Zealand, Eastern Europe, Western Europe, and Northern America, the regions with the highest

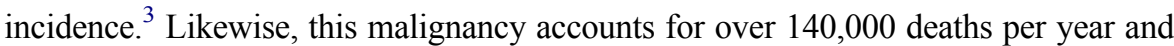
its age-standardized mortality rates can vary depending on geographical settings. ${ }^{3}$
Correspondence: Meisser Madera Department of Research, Faculty of Dentistry at the University of Cartagena, Cartagena, Colombia Tel +5756698172

Email mmaderaa@unicartagena.edu.co 
This disease stands amongst the six most common cancers worldwide, and about $40 \%$ of head and neck tumors are oral squamous cell carcinomas, ${ }^{4}$ which is the most common type of mouth cancers. Moreover, oral cancer has a substantial financial burden on the public healthcare system and produces both physical and psychological impacts on people suffering from this disease such as swallowing function, speech difficulties, and self-image concerns. $^{5}$

Currently, there are important technological advances in cancer management and oncology research, but oral carcinoma still has a poor prognosis and its treatment involves usually severe physical and psychological aftereffects. ${ }^{6,7}$ Amongst the main therapeutic options for oral cancer are surgery, radiotherapy (RT), and chemotherapy (CT); ${ }^{8,9}$ commonly locoregionally oral neoplasms are treated by surgical approach considered as the gold standard treatment, ${ }^{10}$ while those advanced or aggressive oral tumors with high probabilities of relapse after definitive treatment with surgery or RT are treated using a multimodal approach that combines surgery and pre/ postoperative RT or CT. ${ }^{11,12}$ However, for those patients with unresectable disease, when the surgical approach is not feasible because of the extension of lesion, surgery is expected to result in poor functional outcomes, patients' poor status or patient values and preferences, the optimal therapeutic options are largely unclear. ${ }^{13}$

Likewise, it has been reported that the evidence on the benefits of therapeutic interventions for unresectable oral cancer is lacking. ${ }^{14}$ Thus, this review aimed to describe the current scientific evidence about therapeutic options in unresectable oral squamous cell carcinoma.

\section{Methods}

This review followed the Preferred Reporting Items for Systematic Reviews and Meta-Analyses (PRISMA). ${ }^{15}$ The aim and all methods used in this study were specified a priori in a protocol (available on request).

\section{Search Strategy}

We searched MEDLINE (via PubMed) to identify relevant studies assessing any therapeutic options in unresectable oral squamous cell carcinoma. We used MeSH descriptor, free text, and treasure terms such as "mouth neoplasms", "oral cancer", "oral carcinoma", "buccal carcinoma", "unresectable", "advanced", "inoperable", "therapeutics", "treatment", "management" and "therapy" (Supplementary Material 1). There were no language restrictions, and the search was filtered by the last 10 years in order to include the most updated evidence into the review. The last research was carried out on April 12, 2021. Also, a cited reference search was conducted.

\section{Selection of Studies}

Studies of different epidemiological designs (randomized controlled trial (RCT), clinical trial, cohort, and case-control studies) and published after 2010 were included. They had to evaluate any therapeutic option in individuals diagnosed with primary unresectable oral squamous cell carcinoma, defined as patients with advanced mouth neoplasm, no evidence of distant metastases, and unsuitable to surgical treatments for any reason. If a study was reported in more than one publication, only the most recent version was considered. Conversely, studies only on diagnosis and prognosis were excluded. Likewise, studies only focused on interventions before or after surgical treatments were excluded.

We managed all retrieved records using the Rayyan ${ }^{16}$ website. Initially, the duplicates automatically were removed, then at least two appraisers independently screened all titles/abstracts to exclude unrelated studies. Subsequently, full articles were obtained for a final decision. Detailed reasons for exclusion of any study considered relevant were clearly stated.

\section{Methodological Critical Appraisal and Data Extraction}

We critically appraised all included studies using the Joanna Briggs Institute $(\mathrm{JBI})^{17}$ checklist for each study design included in this review. Overall, these checklists rate the quality of different factors such as selection, measurement, and comparability of groups. This tool gives a score for RCT (maximum of 13), clinical trial (maximum of 9), cohort (maximum of 11), and case-control (maximum of 10). There is no cut-off point, so a higher score indicates better methodology quality of the study.

At least two reviewers independently conducted all processes of study selection, methodological critical appraisal, and data extraction. If there were any disagreements, they were resolved by consensus, and when necessary, an additional reviewer participated in the discussion until an agreement was reached. We extracted data about general characteristics of the study (authors, publication year, design, country, aim, sample size, sample features, and risk factors reported) and characteristics of the therapeutic intervention (type, dose, comparison, outcomes, and conclusion 
about its effectiveness). The evidence was organized and presented using tables and narrative synthesis.

\section{Results}

\section{Selection of Studies}

1887 records were identified after removing duplicates. After the title and abstract screening, 68 articles were obtained for final full-text review; 33 studies $^{18-50}$ met the eligibility criteria (Figure 1). The list of excluded studies along with exclusion rationale is available in Supplementary Material 2.

\section{Characteristics of the Included Studies}

All selected studies ${ }^{18-50}$ were published in English language between 2011 and 2020. There were 15 retrospective cohort studies, ${ }^{22,24-26,28,34,36-42,47,50}$ eight were prospective cohort studies, ${ }^{19,23,29,32,33,35,44,46}$ six were RCTs, ${ }^{18,21,27,30,31,43}$ four were clinical trials, ${ }^{20,45,48,49}$ and none was case-control study. The sample size varied from $16^{27}$ to $976^{42}$ participants. There were eight studies from India, ${ }^{19,21,34,36-38,43,46}$ six from Japan, ${ }^{26,27,32,33,40,45}$ four from Taiwan, ${ }^{20,42,47,48}$ three from the United States, ${ }^{25,35,41}$ two from China, ${ }^{30,31}$ two from Pakistan, ${ }^{28,49}$ while the other studies were one from each of the following: Canada, ${ }^{50}$ Hungary, ${ }^{44}$ Italy, ${ }^{23}$ Iran, ${ }^{29}$ Spain, ${ }^{39}$ The Netherlands, ${ }^{24}$ Thailand, ${ }^{22}$ and Ukraine. ${ }^{18}$ Only 14 studies ${ }^{20,22,24,26,28,34-38,41-43,46}$ reported oral cancer risk factors, such as smoking, alcohol consumption and betel chewing. All general characteristics of the selected studies are presented in Supplementary Material 3.

\section{The Methodological Quality of the Included Studies}

Using the JBI's critical appraisal checklist tool, the mean score was $7.5 \pm 2.7$ (range from 2.5 to 10 ), 7.5

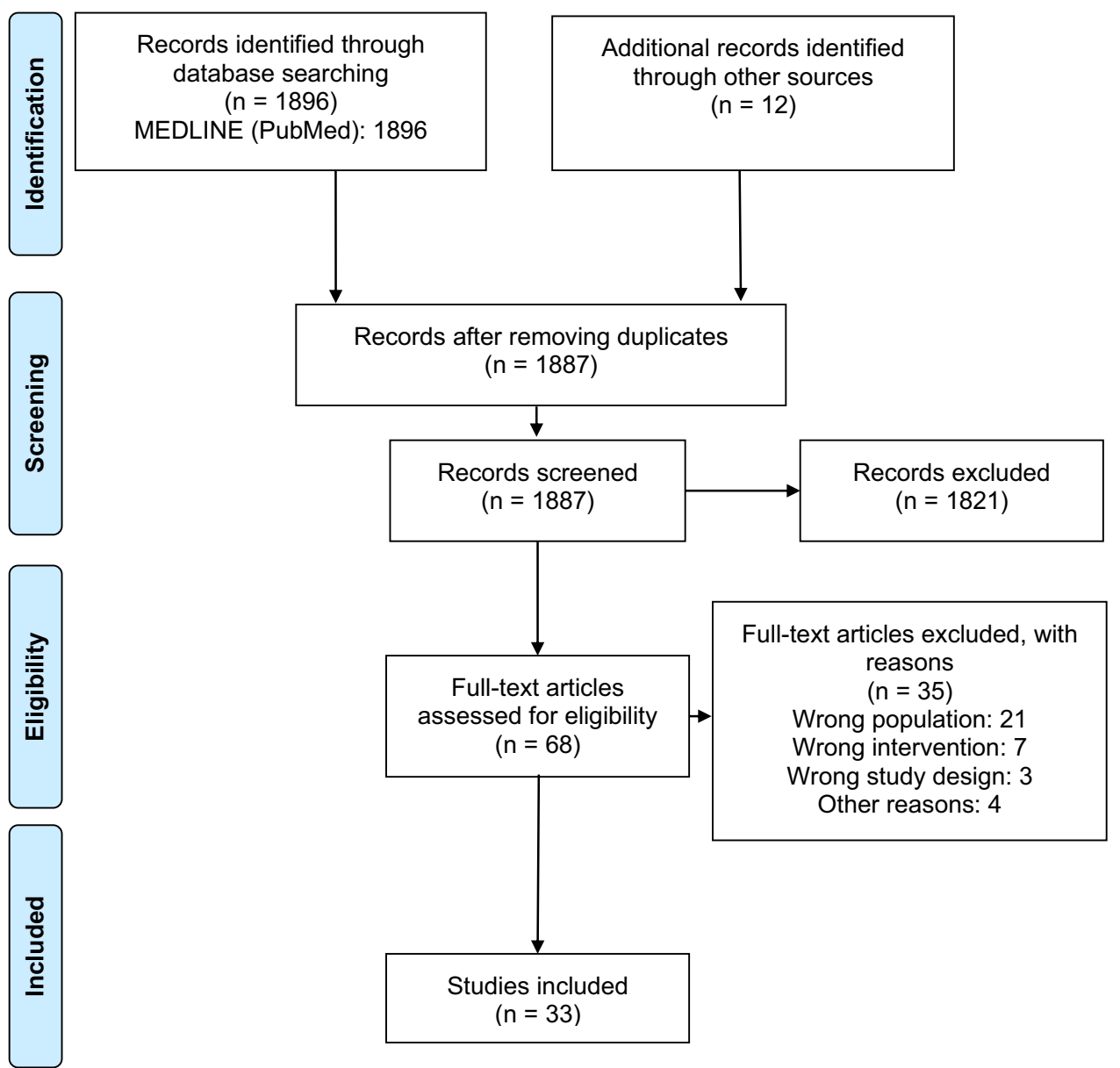

Figure I PRISMA flowchart describing the selection of studies.

Notes: Adapted from Page MJ, McKenzie JE, Bossuyt PM, et al. The PRISMA 2020 statement: an updated guideline for reporting systematic reviews. BMJ. 2021;372:n7I. ${ }^{15}$ Creative Commons Attribution (CC BY 4.0) license (https://creativecommons.org/licenses/by/4.0/legalcode). 


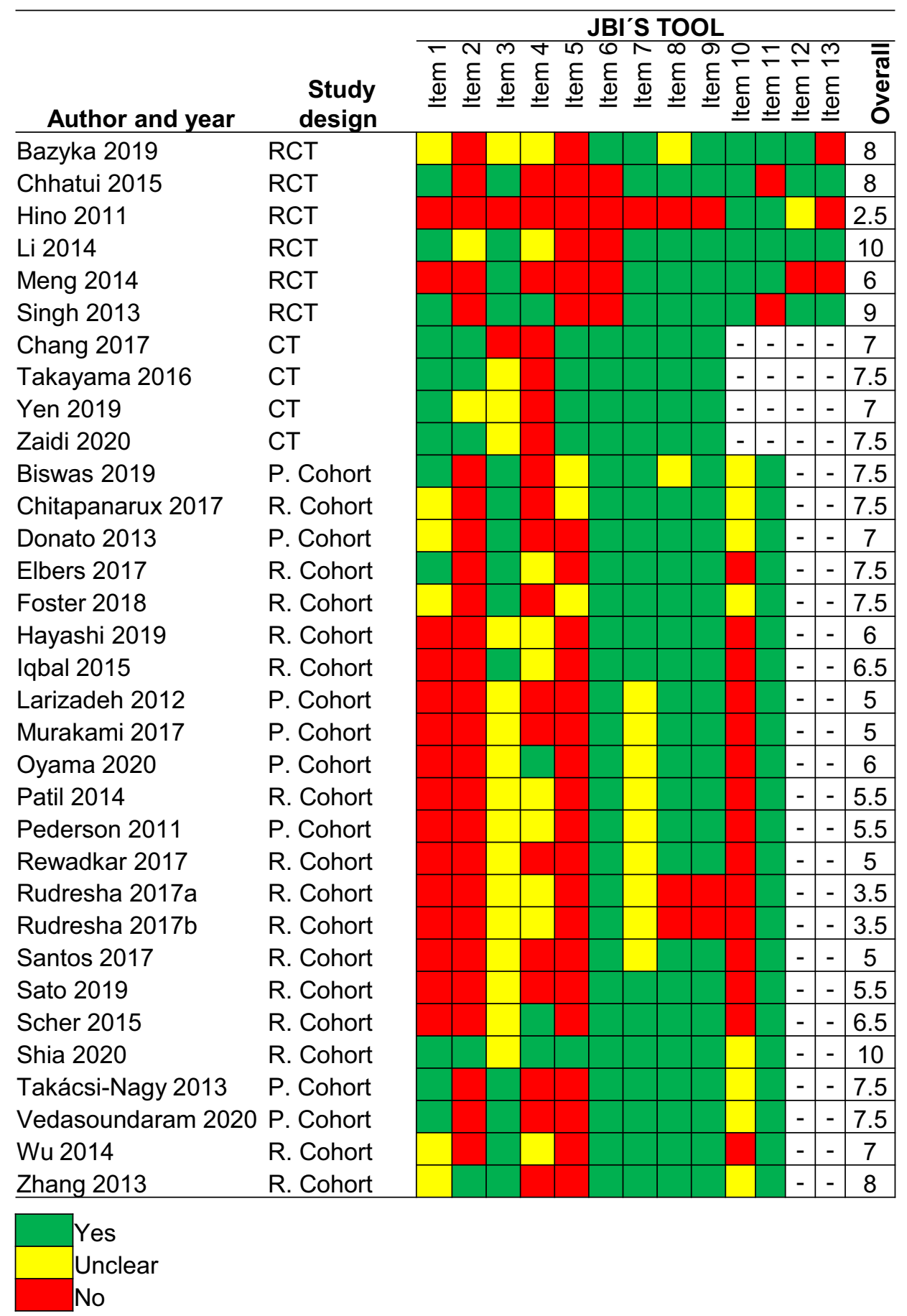

Figure 2 The methodological quality of the included studies by design.

Abbreviations: $C T$, clinical trial; $P$, prospective; $R$, retrospective; $R C T$, randomized controlled trial.

\pm 0.3 (range from 7 to 10 ), and $6.3 \pm 1.5$ (range from 3.5 to 10) for RCTs, clinical trials, and cohort studies, respectively. The results in detail for each study are shown in Figure 2.
Therapeutic Options in Unresectable Oral Squamous Cell Carcinoma

Overall, included studies assessed a variety of therapeutic options in unresectable oral squamous cell carcinoma. 
Twenty-seven studies $^{18,19,21-29,32-42,44-46,49,50}$ assessed different therapies that in some way combined the use of CT and RT, three studies ${ }^{42,43,50}$ evaluated RT alone, two studies $^{31,47}$ assessed CT alone, four studies ${ }^{20,31,43,48}$ examined the combination of targeted therapy plus CT or RT, and only one study for each of the interventions of immunotherapy ${ }^{21}$ and gene therapy. ${ }^{30}$ The main outcomes reported were overall survival (OS), locoregional control (LRC), progression-free survival (PFS), disease-free survival (DFS), complete response (CR), and cancer-specific survival (CSS). All these studies used different approaches, doses, outcomes, etc. Thus, the scientific evidence about the effectiveness of the main treatments for unresectable oral cancer is summarized by groups as follows:

\section{Concurrent Chemoradiotherapy}

Concurrent chemoradiotherapy (CCRT) implies the use of CT delivered simultaneously with RT. This approach has multiple advantages, such as the improvement of the chances of LRC, OS rates, and organ-preserving intent. Moreover, CT given as part of CCRT could act systemically and possibly prevent distant metastases. Likewise, this therapeutic option improves function and cosmetic outcomes compared with surgical approaches. Fourteen studies $^{19,21,24-28,32,33,35,40-42,50}$ evaluated the use of CCRT, two of them were clinical trials, ${ }^{25,27}$ one was a $\mathrm{RCT}^{21}$ and the others were observational studies. ${ }^{19,24,26,28,32,33,35,40-42,50}$ The number of participants for each intervention group varied from $16^{27}$ to $256^{42}$ people. Twelve studies ${ }^{19,21,24-26,28,32,33,35,40,42,50}$ only focused on patients with clinical stage III/IV oral cancer, whereas two studies ${ }^{27,41}$ also included other clinical stages. The main outcomes assessed were OS and LRC, which were evaluated in $10^{24-28,32,33,35,40,41,50}$ and seven $^{24-26,33,35,40,41}$ studies, respectively (Table 1 ).

$\operatorname{Ten}^{19,21,24-28,33,35,40}$ out of $14^{19,21,24-28,32,33,35,40-42,50}$ studies suggested that CCRT is a therapeutic option in people with unresectable oral cancer, so this treatment should be considered when surgery is not feasible. Among those studies in favor of CCRT, the 5-year OS and LRC rates ranged from $22 \%{ }^{24}$ to $76 \%,{ }^{35}$ and $49 \%{ }^{24}$ to $90 \%,{ }^{35}$ respectively. Overall, cisplatin remains as the main chemotherapeutic drug used in CCRT for unresectable oral cancer treatment; three studies ${ }^{19,21,24}$ used cisplatin plus RT up to $70 \mathrm{~Gy}$, one study ${ }^{50}$ used cisplatin or carboplatin plus RT up to $70 \mathrm{~Gy}$, while two studies ${ }^{27,32}$ used the S-1 (Taiho Pharmaceutical, Tokyo, Japan) plus
RT. Biswas ${ }^{19}$ evaluated the use of cisplatin plus RT 70 Gy between younger ( $<40$ years) and older ( $>40$ years) adults, concluding that there is a similar overall response (63.5\% vs $65.9 \%$ ) between these groups; thus, CCRT can be used both for young as the elderly population.

According to the use of $\mathrm{S}-1$, Murakami ${ }^{32}$ reported a 3-year OS and PFS of $37 \%$ and $27 \%$, respectively, employing S-1 plus RT up to 70 Gy. Similarly, Hino ${ }^{27}$ assessed the use of S-1 plus RT 30 Gy and reported a median OS and PFS of 42.5 and 6.3 months, respectively, concluding that CCRT with $\mathrm{S}-1$ is an effective treatment that can be safely conducted with minimal burden on patients. However, it is useful to highlight that that statement should be put into context because there are a small number of studies assessing this approach.

Regarding those studies that used 2-3 drug regimen CT, cisplatin was combined with docetaxel, ${ }^{26,40}$ carboplatin, ${ }^{41}$ gemcitabine, ${ }^{28}$ 5-fluorouracil (5-FU), ${ }^{41}$ and paclitaxel. ${ }^{41}$ Hayashi ${ }^{26}$ evaluated the use of intra-arterial CT (total, 150 $\mathrm{mg} / \mathrm{m}^{2}$ cisplatin and $60 \mathrm{mg} / \mathrm{m}^{2}$ docetaxel) with daily conventional RT (total, $60 \mathrm{~Gy} / 30$ fr) for 6 weeks. At a median follow-up of 40 months, the 3-year OS and LRC were $64.3 \%$ and $84.3 \%$, respectively. Similarly, Sato ${ }^{40}$ evaluated the use of cisplatin combined with docetaxel plus RT up to 66 Gy, reporting a 3-year and 5-year OS and LRC of 52.9\%, $33.0 \%, 50.9 \%$, and $50.9 \%$, respectively. Conversely, some studies $^{41,50}$ have reported poor OS and LRC rates using CCRT in patients with unresectable oral cancer. To illustrate, Zhang $^{50}$ reported a 5 -year OS of just $10 \%$ using cisplatin or carboplatin plus RT up to $70 \mathrm{~Gy}$. Similarly, Scher ${ }^{41}$ reported a 5-year OS of just $15 \%$ using cisplatin combined with carboplatin and 5-FU or paclitaxel plus RT up to $70 \mathrm{~Gy}$. Likewise, Shia ${ }^{42}$ stated that although CCRT has benefits compared to non-treatment, there are no survival differences between the use of RT alone and CCRT.

Overall, CCRT could be considered as the main therapeutic option in unresectable oral squamous cell cancer because there is scientific evidence supporting its use. However, many factors should be taken into account in order to improve the clinical outcomes of these patients, who often are considered beyond cure.

\section{Induction Chemotherapy Followed by Chemoradiotherapy}

Induction chemotherapy (ICT) refers to CT given before the definitive treatment, in this case, that treatment was chemoradiotherapy (CRT). Among the benefits of ICT are 
Table I Summary of Evidence on Concurrent Chemoradiotherapy

\begin{tabular}{|c|c|c|c|c|}
\hline $\begin{array}{l}\text { Author and } \\
\text { Year }\end{array}$ & $\begin{array}{l}\text { Clinical } \\
\text { Stages }\end{array}$ & Interventions & Follow-Up & Outcomes \\
\hline Biswas $2019^{19}$ & $\begin{array}{l}\text { III } \\
\text { IV }\end{array}$ & $\begin{array}{l}\text { Arm I }(n=20): \text { Age }<40 \text { Y, CCRT (cisplatin + RT } 70 \text { Gy) } \\
\text { Arm } 2(n=26): \text { Age }>40 \text { Y, CCRT (cisplatin + RT } 70 \text { Gy }\end{array}$ & $11.1 \mathrm{M}$ & OR: Arm I, 63.5\%; Arm 2, 65.9\% \\
\hline Chhatui $2015^{21}$ & $\begin{array}{l}\text { III } \\
\text { IV }\end{array}$ & (n=25): CCRT (cisplatin + RT 70 Gy) & $15 M$ & $\begin{array}{l}\text { DFS: } 69 \% \\
\text { CR: } 52 \%\end{array}$ \\
\hline Elbers $2017^{24}$ & $\begin{array}{l}\text { III } \\
\text { IV }\end{array}$ & $(n=100): C C R T$ (cisplatin + RT up to $70 \mathrm{~Gy})$ & $13 M$ & $\begin{array}{l}\text { OS [5 Y]: } 22 \% \\
\text { LRC [5 Y]: } 49 \% \\
\text { DFS [5 Y]: } 22 \% \\
\text { DSS [5 Y]: } 39 \%\end{array}$ \\
\hline Foster $2018^{25}$ & $\begin{array}{l}\text { III } \\
\text { IV }\end{array}$ & $(n=140): C C R T(C T+R T$ up to $75 \mathrm{~Gy})$ & $5.7 \mathrm{Y}$ & $\begin{array}{l}\text { OS }[5 \text { Y]: } 63.2 \% \\
\text { LRC }[5 \text { Y]: } 78.6 \% \\
\text { PFS }[5 \text { Y]: } 58.7 \% \\
\text { DC }[5 \text { Y]: } 87.2 \%\end{array}$ \\
\hline Hayashi $2019^{26}$ & $\begin{array}{l}\text { III } \\
\text { IV }\end{array}$ & $(n=46):$ CCRT (docetaxel + cisplatin + RT up to 60 Gy) & $40 \mathrm{M}$ & $\begin{array}{l}\text { OS [3Y]: } 64.3 \% \\
\text { LRC [3Y]: } 84.3 \%\end{array}$ \\
\hline Hino $2011^{27}$ & $\begin{array}{l}\text { II } \\
\text { III } \\
\text { IV }\end{array}$ & $(n=16):$ CCRT (S-I+ RT 30 Gy) & $7.4 \mathrm{M}$ & $\begin{array}{l}\text { OR: } 87.5 \% \\
\text { OS [Median]: } 42.5 \mathrm{M} \\
\text { PFS [Median]: } 6.3 \mathrm{M}\end{array}$ \\
\hline lqbal $2015^{28}$ & $\begin{array}{l}\text { III } \\
\text { IV }\end{array}$ & (n=63): CCRT (gemcitabine + cisplatin + RT 55 Gy) & $60 M$ & $\begin{array}{l}\text { OS }[5 \text { Y]: } 30 \% \\
\text { PFS [5 Y]: } 49 \% \\
\text { DFS [5 Y]: } 30 \%\end{array}$ \\
\hline Murakami $2017^{32}$ & $\begin{array}{l}\text { III } \\
\text { IV }\end{array}$ & $(n=47):$ CCRT (S- $1+$ RT up to $70 \mathrm{~Gy})$ & $22 M$ & $\begin{array}{l}\text { OS }[3 \text { Y]: } 37 \% \\
\text { PFS }[3 \text { Y]: } 27 \%\end{array}$ \\
\hline Oyama $2020^{33}$ & $\begin{array}{l}\text { III } \\
\text { IV }\end{array}$ & $\begin{array}{l}(\mathrm{n}=37): \text { CCRT (docetaxel + } \\
\text { nedaplatin + RT up to } 70 \text { Gy) }\end{array}$ & $40 M$ & $\begin{array}{l}\text { OS [5 Y]: } 64.5 \% \\
\text { DF [5 Y]: } 59.9 \% \\
\text { LC [5 Y]: } 85.5 \%\end{array}$ \\
\hline Pederson $2011^{35}$ & $\begin{array}{l}\text { III } \\
\text { IV }\end{array}$ & $(n=20):$ CCRT (5-FU + hydroxyurea + RT up to $75 \mathrm{~Gy})$ & $60 M$ & $\begin{array}{l}\text { OS [2 Y]: } 76 \% \\
\text { OS [5 Y]: } 76 \% \\
\text { DFS [2 Y]: } 71 \% \\
\text { DFS [5 Y]: } 71 \% \\
\text { LRC [2 Y]: } 90 \% \\
\text { LRC [5 Y]: } 90 \%\end{array}$ \\
\hline Sato $2019^{40}$ & $\begin{array}{l}\text { III } \\
\text { IV }\end{array}$ & $(n=17):$ CCRT (docetaxel+ cisplatin + RT up to 66 Gy) & $4 \mid M$ & $\begin{array}{l}\text { OS [3 Y]: } 52.9 \% \\
\text { OS [5 Y]: } 33.0 \% \\
\text { LRC [3 Y]: } 50.9 \% \\
\text { LRC [5 Y]: } 50.9 \%\end{array}$ \\
\hline Scher $2015^{41}$ & $\begin{array}{l}\text { I } \\
\text { II } \\
\text { III } \\
\text { IV }\end{array}$ & $\begin{array}{l}(n=73): \text { CCRT (cisplatin + carboplatin + 5-FU or paclitaxel + RT up to } 70 \\
\text { Gy) }\end{array}$ & $73.1 \mathrm{M}$ & $\begin{array}{l}\text { OS }[5 \text { Y]: } 15 \% \\
\text { LRC }[5 \text { Y]: } 37.4 \% \\
\text { DC }[5 \text { Y]: } 70.2 \%\end{array}$ \\
\hline Shia $2020^{42}$ & $\begin{array}{l}\text { III } \\
\text { IV }\end{array}$ & $\begin{array}{l}\text { Arm I }(n=256): \text { CCRT } \\
\text { Arm } 2(n=227): \text { Non-treatment }\end{array}$ & $15 M$ & $\begin{array}{l}\text { Death risk: } \\
\text { Arm I, I (Ref); Arm 2, I.60 (I.30- } \\
\text { I.97) }\end{array}$ \\
\hline Zhang $2013^{50}$ & $\begin{array}{l}\text { III } \\
\text { IV }\end{array}$ & $(n=10):$ CCRT (cisplatin or carboplatin + RT up to $70 \mathrm{~Gy})$ & $3.52 \mathrm{Y}$ & $\begin{array}{l}\text { OS [2 Y]: } 20 \% \\
\text { OS [5 Y]: } 10 \% \\
\text { DSS [2 Y]: } 26 \% \\
\text { DSS [5 Y]: } 13 \% \\
\text { DFS [2 Y]: } 13 \%\end{array}$ \\
\hline
\end{tabular}

Abbreviations: CCRT, concurrent chemoradiotherapy; CR, complete response; CT, chemotherapy; DC, distant control; DF, disease free rate; DFS, disease-free survival; DSS, disease specific survival; FU, fluorouracil; LC, local control; LRC, locoregional control; M, months; OR, overall response, OS, overall survival; PFS, progression-free survival; RT, radiotherapy; Y, years. 
to shrink the tumor, decrease the chances of distant metastases, increase the chances of organ preservation, and improving the outcomes such as OS and PFS. Seven studies $^{29,34,36-38,45,49}$ assessed this approach, three studies $^{29,45,49}$ were clinical trials and the rest of studies $^{34,36-38}$ employed observational designs. The number of participants by group varied from $16^{29}$ to $167^{34}$ people. Three studies ${ }^{34,37,38}$ only involved patients with stage IV oral cancer, three studies ${ }^{29,45,49}$ recruited patients with clinical stages III/IV, and one study ${ }^{36}$ did not report it. All studies ${ }^{29,34,36-38,45,49}$ used the 2 or 3 drug regimens $\mathrm{CT}$, and the main outcome reported was OS (Table 2).

In a clinical trial by Larizadeh, ${ }^{29}$ patients with locoregionally advanced oral cancer were enrolled. ICT comprise 3 cycles of cisplatin and 5-FU with or without docetaxel. The overall response rate after ICT was $68.4 \%$, and OS rates after 2 and 3 years were $38 \%$ and $26 \%$, respectively. This author concluded that the outcome of patients with unresectable oral cancer is poor, so the benefits of the use of this therapeutic intervention for these patients are unclear. Likewise, Patil ${ }^{34}$ reported after 2 years an OS rate of $20 \%$ and an LRC of $15.0 \%$ for patients who underwent ICT with multiple drugs (paclitaxel or docetaxel plus cisplatin or carboplatin with or without 5-FU) followed by CCRT (cisplatin plus RT up to 70 Gy).

In terms of CR, two studies ${ }^{36,49}$ reported this outcome. Rewadkar ${ }^{36}$ reported a CR of $84 \%$ using bleomycin, methotrexate, and cisplatin on day 1 and repeated at an interval of 21 days during 3 cycles; then, participants were treated with CCRT using cisplatin infusion. That study stated that this approach can be superior to other treatments such as ICT plus RT alone. Conversely, Zaidi ${ }^{49}$ conducted an open-label, non-randomized trial and reported a complete response of just $10.5 \%$ using ICT with docetaxel plus cisplatin followed by cisplatin plus concurrent RT up to 60 Gy.

Takayama $^{45}$ evaluated a complex approach using ICT followed by CCRT in 33 patients with stage III-IVB tongue cancer. Briefly, after two systemic CT courses and whole-neck irradiation using 36 Gy in 20 fractions, CCRT was used comprising proton beam therapy with weekly retrograde intra-arterial CT by continuous infusion of cisplatin with sodium thiosulfate. At a median follow-up of 43 months, the 3-year OS, PFS, local control (LC) rates were $87.0 \%, 74.1 \%$ and $86.6 \%$, respectively. Overall, although ICT followed by CCRT can be used as a therapeutic option in unresectable oral cancer, its potential benefits still are controversial.

\section{Induction Chemotherapy Followed by \\ Radiotherapy}

Four studies ${ }^{18,36-38}$ assessed this approach, one of them was an $\mathrm{RCT},{ }^{18}$ and the others were retrospective cohort studies, ${ }^{36-38}$ the number of participants by intervention group varied from $8^{37}$ to $99^{18}$ people. Two studies ${ }^{37,38}$ included patients with clinical stage IV oral cancer, while two studies ${ }^{18,36}$ did not report it. All studies ${ }^{18,36-38}$ used the 2 or 3 drug regimen involving chemotherapeutic drugs, such as cisplatin, carboplatin, 5-FU, bleomycin, polyplatilene, methotrexate, paclitaxel, and docetaxel. The main outcome was OS, which was evaluated in three studies $^{18,37,38}$ (Table 3).

One $\mathrm{RCT}^{18}$ have examined the role the ICT followed by RT in patients with locally advanced oral cavity, suggesting in terms of OS, that the use of ICT with polyplatilene plus 5-FU followed by RT 70 Gy is better than using ICT with cisplatin plus 1,5-FU followed by RT 70 Gy (36 months OS $=58 \%$ vs $29 \%$ ). Two observational studies ${ }^{37,38}$ reported only a median OS of 7.3 and 8.5 months for patients treated with ICT followed by RT, which suggests that other therapeutic options should be considered in order to improve the disease-related outcomes.

\section{Radiotherapy with/without Chemotherapy}

All studies assessing RT alone or RT with or without CT were included in this group. Overall, five studies $^{22,23,42,43,50}$ assessed this approach, three studies $^{42,43,50}$ assessed RT alone and two studies ${ }^{22,23}$ assessed RT with or without CT. There was an $\mathrm{RCT},{ }^{43}$ a clinical trial ${ }^{23}$ and three observational studies..$^{22,42,50}$ The number of participants for each group ranged from $9^{23}$ to $315^{22}$ people. All studies ${ }^{22,23,42,43,50}$ recruited patients with stage III/IV oral cancer (Table 4).

Among the studies assessing RT alone, one study ${ }^{50}$ reported a 2-year and 5-year OS of just $18 \%$ and $10 \%$, respectively. One study ${ }^{43}$ reported a CR of $33 \%$, whereas another study ${ }^{42}$ reported that the death risk for those receiving non-treatment was approximately $60 \%$ higher than those receiving RT alone. Among those evaluating the use of RT with or without CT, Donato ${ }^{23}$ reported a 2-year OS and DFS of $55.6 \%$ and $75 \%$, respectively. Conversely, Chitapanarux ${ }^{22}$ reported a 5 -year OS of just $15.9 \%$. Overall, there is no strong evidence to support this approach to treat patients suffering from unresectable oral cancer. 
Table 2 Summary of Evidence on Induction Chemotherapy Followed by Chemoradiotherapy

\begin{tabular}{|c|c|c|c|c|}
\hline $\begin{array}{l}\text { Author } \\
\text { and Year }\end{array}$ & $\begin{array}{l}\text { Clinical } \\
\text { Stages }\end{array}$ & Interventions & Follow-Up & Outcomes \\
\hline $\begin{array}{l}\text { Larizadeh } \\
2012^{29}\end{array}$ & $\begin{array}{l}\text { III } \\
\text { IV }\end{array}$ & $\begin{array}{l}\text { Arm I }(n=16) \text { : ICT with cisplatin + 5-FU followed by CCRT (cisplatin + RT) } \\
\text { Arm } 2(n=4 I): I C T \text { with cisplatin + 5-FU + docetaxel followed by CCRT } \\
\text { (cisplatin + RT) }\end{array}$ & $32 M$ & $\begin{array}{l}\text { OR: } 68.4 \% \\
\text { OS [2 Y]: } 38 \% \\
\text { OS [3 Y]: } 26 \% \\
\text { OS [Mean]: Arm I, I7.I } \\
\text { M; Arm 2, } 27.9\end{array}$ \\
\hline $\begin{array}{l}\text { Patil } \\
2014^{34}\end{array}$ & IV & $\begin{array}{l}\text { ( } n=167 \text { ): ICT with paclitaxel or docetaxel }+ \text { cisplatin or carboplatin } \pm 5 \text {-FU } \\
\text { followed by CCRT (cisplatin + RT up to } 70 \mathrm{~Gy} \text { ) }\end{array}$ & $28 M$ & $\begin{array}{l}\text { OS }[2 \text { Y]: } 20 \% \\
\text { LRC }[2 \text { Y]: I5.0\% }\end{array}$ \\
\hline $\begin{array}{l}\text { Rewadkar } \\
2017^{36}\end{array}$ & NR & $\begin{array}{l}(n=25): \text { ICT with bleomycin + methotrexate + cisplatin followed by CCRT } \\
\text { (cisplatin + RT) }\end{array}$ & NR & CR: $84 \%$ \\
\hline $\begin{array}{l}\text { Rudresha } \\
2017 a^{37}\end{array}$ & IV & $(n=27)$ : ICT with paclitaxel + carboplatin followed by CCRT & NR & OS [Median]: II.8 M \\
\hline $\begin{array}{l}\text { Rudresha } \\
2017 b^{38}\end{array}$ & IV & $\begin{array}{l}(\mathrm{n}=44) \text { : ICT with docetaxel + cisplatin }+5-\mathrm{FU} \text { or paclitaxel + carboplatin } \\
\text { followed by CCRT }\end{array}$ & NR & OS [Median]: $9.4 \mathrm{M}$ \\
\hline $\begin{array}{l}\text { Takayama } \\
2016^{45}\end{array}$ & $\begin{array}{l}\text { III } \\
\text { IV }\end{array}$ & $\begin{array}{l}(\mathrm{n}=33) \text { : ICT with 5-FU + nedaplatin + RT } 36 \text { Gy followed by CCRT (5-FU + } \\
\text { nedaplatin + RT } 39.6 \mathrm{~Gy}+\text { cisplatin) }\end{array}$ & $43 M$ & $\begin{array}{l}\text { OS }[3 \text { Y]: } 87.0 \% \\
\text { PFS }[3 \text { Y]: } 74.1 \% \\
\text { LC }[3 \text { Y]: } 86.6 \%\end{array}$ \\
\hline $\begin{array}{l}\text { Zaidi } \\
2020^{49}\end{array}$ & $\begin{array}{l}\text { III } \\
\text { IV }\end{array}$ & $\begin{array}{l}(n=35): \text { ICT with docetaxel + cisplatin followed by CCRT (cisplatin + RT up to } \\
60 \mathrm{~Gy})\end{array}$ & $4 \mathrm{M}$ & $\begin{array}{l}\text { OR: } 78.8 \% \\
\text { CR: } 10.5 \% \\
\text { PR: } 68.4 \%\end{array}$ \\
\hline
\end{tabular}

Abbreviations: CCRT, concurrent chemoradiotherapy; CR, complete response; FU, fluorouracil; ICT, induction chemotherapy; LC, local control; LRC, locoregional control; M, months; NR, not reported; OR, overall response, OS, overall survival; PFS, progression-free survival; PR, partial response, RT, radiotherapy; Y, years.

Table 3 Summary of Evidence on Induction Chemotherapy Followed by Radiotherapy

\begin{tabular}{|c|c|c|c|c|}
\hline $\begin{array}{l}\text { Author and } \\
\text { Year }\end{array}$ & $\begin{array}{l}\text { Clinical } \\
\text { Stages }\end{array}$ & Interventions & Follow-Up & Outcomes \\
\hline $\begin{array}{l}\text { Bazyka } \\
2019^{18}\end{array}$ & NR & $\begin{array}{l}\text { Arm I }(n=99) \text { : ICT with cisplatin + I.5-FU followed by RT up to } 70 \\
\text { Gy } \\
\text { Arm } 2(n=43) \text { : ICT with polyplatilene + 5-FU followed by RT up to } \\
70 \text { Gy }\end{array}$ & NR & $\begin{array}{l}\text { OS [36 M]: Arm I, 29\%*; } \\
\text { Arm } 2,58 \% *\end{array}$ \\
\hline $\begin{array}{l}\text { Rewadkar } \\
2017^{36}\end{array}$ & NR & $\begin{array}{l}(n=25) \text { : ICT with bleomycin + methotrexate }+ \text { cisplatin followed by } \\
\text { RT up to } 70 \text { Gy }\end{array}$ & NR & CR: $60 \%$ \\
\hline $\begin{array}{l}\text { Rudresha } \\
2017 a^{37}\end{array}$ & IV & $(n=8)$ : ICT with paclitaxel + carboplatin followed by RT & NR & OS [Median]: $8.5 \mathrm{M}$ \\
\hline $\begin{array}{l}\text { Rudresha } \\
2017 b^{38}\end{array}$ & IV & $\begin{array}{l}(n=I I): \text { ICT with docetaxel + cisplatin + 5-FU or paclitaxel + } \\
\text { carboplatin followed by RT }\end{array}$ & NR & OS [Median]: $7.3 \mathrm{M}$ \\
\hline
\end{tabular}

Note: *Data extracted from a figure.

Abbreviations: CR, complete response; FU, fluorouracil; ICT, induction chemotherapy; M, months; NR, not reported; OS, overall survival; RT, radiotherapy.

\section{Radiotherapy with or without} Chemotherapy Followed by Brachytherapy Three studies ${ }^{39,44,46}$ focused on the use of external beam RT (EBRT) with or without concurrent CT followed by brachytherapy (BT), two of them were clinical trials ${ }^{44,46}$ and one was a retrospective cohort study. ${ }^{39}$ The number of participants for each intervention group varied from $24^{39}$ to $60^{44}$ people. One study ${ }^{39}$ included patients with clinical stage III/IV oral cancer, one study ${ }^{46}$ only included patients with stage III oral cancer, and another study ${ }^{44}$ also 
Table 4 Summary of Evidence on Radiotherapy with/without Chemotherapy

\begin{tabular}{|c|c|c|c|c|}
\hline Author and Year & $\begin{array}{l}\text { Clinical } \\
\text { Stages }\end{array}$ & Interventions & Follow-Up & Outcomes \\
\hline $\begin{array}{l}\text { Chitapanarux } \\
2017^{22}\end{array}$ & $\begin{array}{l}\text { III } \\
\text { IV }\end{array}$ & $(n=315):$ RT $60-70$ Gy $\pm C T$ & II M & $\begin{array}{l}\text { OS }[5 \mathrm{Y}]: 15.9 \% \\
\text { OS }[10 \mathrm{Y}]: 12.9 \%\end{array}$ \\
\hline Donato $2013^{23}$ & $\begin{array}{l}\text { III } \\
\text { IV }\end{array}$ & $(n=9): R T$ up to $70 \mathrm{~Gy} \pm \mathrm{CT}$ & $24 M$ & $\begin{array}{l}\text { OR: } 77.8 \% \\
\text { OS [2 Y]: } 55.6 \% \\
\text { DFS [2 Y]: } 75 \%\end{array}$ \\
\hline Shia $2020^{42}$ & $\begin{array}{l}\text { III } \\
\text { IV }\end{array}$ & $\begin{array}{l}\text { Arm I }(n=237): \text { RT } \\
\text { Arm } 2(n=227): \text { Non- } \\
\text { treatment }\end{array}$ & $15 M$ & $\begin{array}{l}\text { Death risk: Arm I, I.06 (0.87, I.3I); Arm 2, I.60 (I.30, } \\
\text { I.97) }\end{array}$ \\
\hline Singh $2013^{43}$ & $\begin{array}{l}\text { III } \\
\text { IV }\end{array}$ & $(n=30): R T 70$ Gy & $20 M$ & CR: $33 \%$ \\
\hline Zhang $2013^{50}$ & $\begin{array}{l}\text { III } \\
\text { IV }\end{array}$ & $(n=28):$ RT up to $80 G y$ & $3.52 \mathrm{Y}$ & $\begin{array}{l}\text { OS [2 Y]: } 18 \% \\
\text { OS [5 Y]: } 10 \% \\
\text { DSS [2 Y]: } 21 \% \\
\text { DSS [5 Y]: } 21 \% \\
\text { DFS [2 Y]: } 21 \% \\
\text { DFS [5 Y]: } 21 \%\end{array}$ \\
\hline
\end{tabular}

Abbreviations: CR, complete response; CT, chemotherapy; DFS, disease-free survival; DSS, disease specific survival; $M$, months; OR, overall response, OS, overall survival; $\mathrm{RT}$, radiotherapy; Y, years.

included other clinical stages. The main outcomes assessed were OS, LRC, and CSS, which were evaluated in two $\mathrm{t}^{39,44}$ out of three $e^{39,44,46}$ studies (Table 5).

In a nonrandomized clinical trial by Takácsi-Nagy, ${ }^{44}$ a high-dose-rate (HDR) BT boost with a mean dose of 17 Gy was delivered after 50-70 Gy locoregional EBRT. Moreover, around $30 \%$ of participants also received concurrent $\mathrm{CT}$ with cisplatin, reporting that the 5 -year rate of LC, LRC, OS, and CSS was $57 \%, 50 \%, 47 \%$, and $61 \%$, respectively. Furthermore, OS was significantly better in patients receiving concurrent CT $(69 \%$ vs $39 \%$; $\mathrm{p}=0.005)$. Santos ${ }^{39}$ assessed the use of EBRT up to 60 Gy plus concurrent CT followed by HDR-BT up to 24 Gy with a median follow-up of 44 months, reporting that the 4 -year OS and LRC rate was $68 \%$ and $80 \%$, respectively. Similarly, Vedasoundaram ${ }^{46}$ assessed the use of EBRT 50 Gy plus CT with cisplatin followed by HDRBT 21 Gy and reported a CR of $77.2 \%$. Overall, this approach seems to be effective to treat patients with unresectable oral cancer, but more research about it is needed.

\section{Chemotherapy}

Two studies ${ }^{31,47}$ evaluated the use of CT, one of them was a controlled clinical trial, ${ }^{47}$ and another was an observational retrospective study. ${ }^{31}$ One study ${ }^{47}$ included 21 participants in the intervention group, whereas the other study $^{31}$ included just 8 people in the intervention group. All two studies ${ }^{31,47}$ focused on patients with clinical stage III/IV oral cancer.

$\mathrm{Wu}^{47}$ aimed to assess the efficacy of intra-arterial infusion CT for patients with locally advanced oral cancer. Patients received continuously an infusion of methotrexate $(50 \mathrm{mg} /$ day) into the external carotid artery for 8 days, followed by a weekly intra-arterial bolus of $25 \mathrm{mg}$ methotrexate for 10 weeks. Overall, CR and the partial response rate were $62 \%$ and $33 \%$, respectively. At a median followup of 69 months, the 1-year, 3-year, and 5-year OS rates were $80 \%, 71 \%$, and $64 \%$, respectively. Similarly, Meng ${ }^{31}$ evaluated the use of the docetaxel-cisplatin-FU regimen, showing a response rate of $37.5 \%$ and a disease control rate of $62.5 \%$. However, few studies are assessing the use of CT alone for unresectable oral cancer, so its effectiveness should be determined.

\section{Targeted Therapy, Immunotherapy, and Gene Therapy}

Six studies $^{20,21,30,31,43,48}$ were included in this group, four $^{20,31,43,48}$ of them assessed therapeutic options for unresectable oral cancer including at least a drug 
Table 5 Summary of Evidence on Radiotherapy with or without Chemotherapy Followed by Brachytherapy

\begin{tabular}{|c|c|c|c|c|}
\hline $\begin{array}{l}\text { Author and } \\
\text { Year }\end{array}$ & $\begin{array}{l}\text { Clinical } \\
\text { Stages }\end{array}$ & Interventions & Follow-Up & Outcomes \\
\hline Santos $2017^{39}$ & $\begin{array}{l}\text { III } \\
\text { IV }\end{array}$ & $(n=24):$ EBRT up to $60 \mathrm{~Gy}+\mathrm{CT}$ followed by HDR-BT & $44 M$ & $\begin{array}{l}\text { OS [3 Y]: } 68 \% \\
\text { OS [4 Y]: } 68 \% \\
\text { CSS [3 Y]: } 75 \% \\
\text { CSS [4 Y]: } 68 \% \\
\text { LC [3 Y]: } 80 \% \\
\text { LC [4 Y]: } 80 \% \\
\text { LRC [3 Y]: } 84 \% \\
\text { LRC [4 Y]: } 76 \% \\
\text { DFS [3 Y]: } 62 \% \\
\text { DFS [4 Y]: } 48 \%\end{array}$ \\
\hline $\begin{array}{l}\text { Takácsi-Nagy } \\
2013^{44}\end{array}$ & $\begin{array}{l}\text { I } \\
\text { II } \\
\text { III } \\
\text { IV }\end{array}$ & $\begin{array}{l}\text { ( } n=60) \text { : EBRT up to } 70 \mathrm{~Gy} \pm \mathrm{CT} \text { with cisplatin followed by } \\
\text { HDR-BT up to } 30 \mathrm{~Gy}\end{array}$ & $121 \mathrm{M}$ & $\begin{array}{l}\text { OS [5Y]: } 47 \% \\
\text { LRC [5Y]: } 50 \% \\
\text { LC [5Y]: } 57 \% \\
\text { CSS [5Y]: } 61 \%\end{array}$ \\
\hline $\begin{array}{l}\text { Vedasoundaram } \\
2020^{46}\end{array}$ & III & $\begin{array}{l}\text { ( } n=57) \text { : EBRT } 50 \mathrm{~Gy}+\mathrm{CT} \text { with cisplatin followed by HDR- } \\
\text { BT up to } 2 \text { I Gy }\end{array}$ & $60 M$ & CR: $77.2 \%$ \\
\hline
\end{tabular}

Abbreviations: CT, chemoradiotherapy; CR, complete response; CSS, cancer specific survival; DFS, disease-free survival; EBRT, external beam radiotherapy; HDR-BT, high dose rate brachytherapy; LC, local control; LRC, locoregional control; M, months; OS, overall survival; RT, radiotherapy; Y, years.

considered as targeted therapy, one study ${ }^{21}$ assessed the use of immunotherapy plus ICT followed by CRT, and one study ${ }^{30}$ evaluated the use of gene therapy plus CT. There were three $\mathrm{RCTs}^{21,30,43}$ and three clinical trials. ${ }^{20,31,48}$ The number of participants for each intervention group varied from $9^{31}$ to $43^{20}$ people. Two studies ${ }^{20,48}$ only focused on patients with clinical stage IV oral cancer, whereas four studies $^{21,30,31,43}$ focused on patients with stages III/IV. The main outcome assessed was OS, which was assessed in three ${ }^{20,30,48}$ out of $\operatorname{six}^{20,21,30,31,43,48}$ studies (Table 6).

Two studies ${ }^{20,48}$ included the use of cetuximab in their treatment regimen. An open-label Phase II trial by Chang $^{20}$ evaluated a regimen comprising cetuximabdocetaxel-cisplatin, and 5-FU followed by bio-CRT with cisplatin and cetuximab; the 1-year OS and PFS were 68\% and $43 \%$, respectively. This author stated that this approach is an effective and tolerable ICT regimen for inoperable oral cancer. Likewise, a phase II clinical trial by $\mathrm{Yen}^{48}$ assessed the neoadjuvant cetuximab plus paclitaxel, and cisplatin followed by cetuximab-based RT 70 Gy; and reported an overall response rate of $70.2 \%$ and a median OS of 15.2 months. Another study ${ }^{31}$ tested the use of nimotuzumab combined with the docetaxel-cisplatin -FU regimen, reporting a response rate of $89.9 \%$ and disease control rates of $100 \%$, suggesting that this regimen is effective and safe in the treatment of advanced oral squamous cell carcinoma. Similarly, Singh ${ }^{43}$ assessed the use of gefitinib plus RT $70 \mathrm{~Gy}$, showing a CR of $60 \%$ and suggesting that this intervention has better outcomes compared to RT alone.

Chhatui $^{21}$ conducted an RCT assessing the ICT with cisplatin plus 5-FU regimen for three cycles and interferon alpha $2 b$, which was subcutaneously given at the dose of $3 \mathrm{MU}$, biweekly for three weeks. Then, the participants received CRT with cisplatin $30 \mathrm{mg} / \mathrm{m}^{2} /$ week and RT 70 Gy. This author reported a CR and DFS of $64 \%$ and $87 \%$, respectively; concluding that this approach may produce superior outcomes. However, it is useful to highlight that there is limited evidence about it. Thus, the effectiveness of treatments involving immunotherapy for unresectable oral cancer is uncertain.

A Phase III RCT ${ }^{30}$ aimed to assess a combination of recombinant adenoviral p53 (rAd-p53) gene therapy and intra-arterial delivery of CT agents for the treatment of oral squamous cell carcinoma. In that study, 99 participants were recruited and randomly divided into three arms: $\operatorname{arm~I~}(\mathrm{n}=35$; intra-arterial infusion of rAd-p53 plus CT), arm II ( $\mathrm{n}=33$; intra-arterial infusion of rAdp53 plus placebo CT), and arm III $(n=31$; intra-arterial infusion of placebo rAd-p53 plus CT). The 5-year OS rate was $48.5 \%, 30 \%$ and $22.5 \%$ for arm 1 , arm 2 and arm 3 , respectively. These findings suggest that the use of 
Table 6 Summary of Evidence on Targeted Therapy, Immunotherapy and Gene Therapy

\begin{tabular}{|c|c|c|c|c|}
\hline $\begin{array}{l}\text { Author } \\
\text { and Year }\end{array}$ & $\begin{array}{l}\text { Clinical } \\
\text { Stages }\end{array}$ & Interventions & $\begin{array}{l}\text { Follow- } \\
\text { Up }\end{array}$ & Outcomes \\
\hline $\begin{array}{l}\text { Chang } \\
2017^{20}\end{array}$ & IV & $\begin{array}{l}(n=43): \text { cetuximab }+ \text { docetaxel }+ \text { cisplatin }+5 \text {-FU followed by bio- } \\
\text { CRT with cisplatin and cetuximab }\end{array}$ & $15 M$ & $\begin{array}{l}\text { OS [I Y }]: 68 \% \\
\text { PFS [I Y }]: 43 \%\end{array}$ \\
\hline $\begin{array}{l}\text { Chhatui } \\
2015^{21}\end{array}$ & $\begin{array}{l}\text { III } \\
\text { IV }\end{array}$ & $\begin{array}{l}\text { ( } n=25): \text { ICT with cisplatin + 5-FU + interferon } \alpha-2 b \text { followed by CRT } \\
\text { (cisplatin + RT } 70 \mathrm{~Gy})\end{array}$ & $15 M$ & $\begin{array}{l}\text { CR: } 64 \% \\
\text { DFS: } 87 \%\end{array}$ \\
\hline Li $2014^{30}$ & $\begin{array}{l}\text { III } \\
\text { IV }\end{array}$ & $\begin{array}{l}\text { Arm I }(n=35): \text { rAd-p } 53+C T \\
\text { Arm } 2(n=33): \text { rAd-p53 + placebo CT } \\
\text { Arm } 3(n=31): \text { placebo rAd-p53 + CT }\end{array}$ & $36 \mathrm{M}$ & $\begin{array}{l}\text { CR: Arm I, 48.5\%; Arm 2, 16.7\%, } \\
\text { Arm 3, } 17.2 \%\end{array}$ \\
\hline $\begin{array}{l}\text { Meng } \\
2014^{31}\end{array}$ & $\begin{array}{l}\text { III } \\
\text { IV }\end{array}$ & $(n=9):$ nimotuzumab + docetaxel + cisplatin $+5-\mathrm{FU}$ & NR & $\begin{array}{l}\text { RR: } 89.9 \% \\
\text { DCR: } 100 \%\end{array}$ \\
\hline $\begin{array}{l}\text { Singh } \\
2013^{43}\end{array}$ & $\begin{array}{l}\text { III } \\
\text { IV }\end{array}$ & $(n=30):$ gefitinib + RT $70 \mathrm{~Gy}$ & $20 M$ & CR: $60 \%$ \\
\hline Yen $2019^{48}$ & IV & $\begin{array}{l}(n=39): \text { cetuximab + paclitaxel + cisplatin followed by BioRT } \\
\text { (cetuximab + RT 70Gy) }\end{array}$ & $6.5 \mathrm{Y}$ & $\begin{array}{l}\text { OR: } 70.2 \% \\
\text { CR: } 8.5 \% \\
\text { PR: } 61.7 \% \\
\text { PFS [Median]= } 10.3 \mathrm{M} \\
\text { OS [Median]= } 15.2 \mathrm{M}\end{array}$ \\
\hline
\end{tabular}

Abbreviations: CR, complete response; CRT, chemoradiotherapy; CT, chemotherapy; DCR, disease control rate; DFS, disease-free survival; FU, fluorouracil; ICT, induction chemotherapy; M, months; NR, not reported; OR, overall response; OS, overall survival; PFS, progression-free survival; PR, partial response; rAd-p53, recombinant adenoviral p53; RR, response rate; RT, radiotherapy; Y, years.

rAd-p53 gene therapy plus $\mathrm{CT}$ can improve the clinical outcomes for people suffering from unresectable oral cancer, but these results should be considered with caution since there is lacking evidence about the effectiveness of these treatment options.

\section{Discussion}

In order to describe the main therapeutic options in unresectable oral squamous cell carcinoma, we conducted an evidence-based comprehensive analysis. This review may be the first one focused on unresectable oral cancer since we did not find any previous report. Moreover, other reviews focused on oral cancer treatment usually based their conclusions on studies including a large proportion of patients with other types of cancers such as head and neck tumors, and just a small proportion of people suffering from oral cancer.

Our findings suggest that the optimal treatment of patients with unresectable oral cancer is challenging; thus, there is a sprinkling of studies proposing a range of therapeutic options, such as RT, CT, CCRT, immunotherapy, targeted therapy plus CT or RT, and gene therapy plus CT. However, it is useful to highlight that the scientific evidence supporting many of these approaches is limited. Overall, the use of CCRT, and ICT followed by CRT have shown good clinical results such as improvement of overall response, ${ }^{49}$ OS and LCR rate. ${ }^{35}$ In this sense, most studies $^{19,24-28,33,35,40}$ supported the use of the CCRT as a therapeutic option in people with unresectable oral cancer. Likewise, some studies ${ }^{36,45,49}$ indicated the benefits of the use of ICT followed by CRT for the treatment of these patients. Consequently, these therapeutic options can be useful when surgery is not feasible.

However, some factors should be considered to choose the optimal therapeutic options in unresectable oral squamous cell carcinoma. Firstly, the treatment side effects; to illustrate, Chhatui ${ }^{21}$ reported that those patients receiving ICT had more toxicities and treatment interruptions; among its side effects were skin reactions, mucositis, anemia, leukopenia, nausea, and vomiting. Similarly, Sato ${ }^{40}$ reported that among the adverse effects of using CCRT are stomatitis, dermatitis, anemia, and liver dysfunction. Secondly, individual patient factors and their possible role on the treatment effect should be taken into account. Some reports suggest that differences in lifestyle, living environment, and race, may affect the therapy effectiveness in oncology. ${ }^{51-53}$ For example, diet management improves OS and other clinical outcomes in people with head and neck cancers. ${ }^{51}$ Likewise, after oral cancer treatment, black people usually have poorer 
OS rates than whites. ${ }^{52}$ Moreover, changes in habits such as quitting smoking, alcohol drinking, and betel nut could have a considerable impact on therapeutic interventions, especially in patients with unresectable oral cancer. ${ }^{53}$ However, we highlight that few studies ${ }^{20,22,24,26,28,34-38,41-43,46}$ in this review reported those factors, and only one study ${ }^{22}$ analyzed the influence of them on treatment response. Finally, the reasons given to determine whether the tumor was unresectable should be considered; since unresectable oral neoplasms due to technical reasons could have different treatment responses compared with those unresectable tumors due to patients' comorbidities or poor general health status. ${ }^{13}$ Overall, any treatment should be judged and discussed with a multidisciplinary team, evaluating its risks and benefits.

Our findings may be comparable with the results reported by Alzahrani, ${ }^{13}$ who narratively reviewed the evidence on the optimal care for people suffering from locally advanced oral cancer, concluding that when surgery is not recommended, these patients can be treated by curative CRT. In addition, this author suggested the use of ICT before surgery or CRT for unresectable oral cancers. However, these results should be taken with caution since there are some differences between these two reviews; firstly, most studies included in the Alzahrani ${ }^{13}$ review had focused on head and neck cancers, while our review included studies exclusively focused on oral cancer, or those studies showing results separately for this oral disease. Secondly, since our main goal was to describe the therapeutic options when surgery is not feasible, we did not consider interventions before or after surgical treatments, which intent to become an unresectable lesion to an operable one or to provide adjuvant therapy. ${ }^{54,55}$

Similarly, our findings also should be put into context. So initially, as it has been previously reported, there is limited evidence of therapeutic options in unresectable oral cancer. ${ }^{14}$ Secondly, most studies ${ }^{19,22-26,28,29,32-42,44,46,47,50}$ included in this review had an observational design and many of them conducted a retrospective analysis, 22,24-26,28,34,36-42,47,50 therefore their conclusions may be biased since observational studies are not the best design to assess the effectiveness of treatments; so high-quality RCTs must be conducted, which have major relevance for clinical practice. ${ }^{56}$ Finally, the methodological quality of some studies $26,27,29,31,32,34-38,40$ was suboptimal using the JBI's tool. Thus, any therapeutic option in this review should be analyzed and interpreted considering the limitations of each selected study.

The main practical implications of this review are related to helping practitioners and patients in the decision-making process. Given knowing the available evidence and its quality is so important to provide evidence-based health care, the findings of this review can be useful to improve the management of oral cavity cancer. In this sense, those interventions identified as beneficial could be considered into dental clinical practice to provide evidence-based dentistry. Similarly, those treatments that have been used for decades without evidence' support, and have no potential benefits, should not be considered as options to treat unresectable mouth cancers. However, it is useful to highlight that this review does not pretend to replace any clinical practice guideline. Thus, any treatment should be adapted for each patient considering the clinical expertise, the available resources, their risk/benefit ratio, and other contextual aspects. ${ }^{57}$

Another potential implication of this review is related to conduct high-quality research on those interventions with lacking evidence such as gene therapy, which had only one selected study. ${ }^{30}$ In this sense, cancer gene therapy is considered a novel approach that may significantly improve clinical outcomes such as OS of patients suffering from cancers. ${ }^{58,59}$ Likewise, it is useful to mention that more research on targeted therapy is needed. All these new therapeutic approaches have been developed on a better understanding of molecular mechanisms involved in the cancer disease; thus, they are more selective against tumor cells, which leads to decrease in side effects. However, their clinical applicability to treat head and neck cancers still is unclear. ${ }^{60}$

Some limitations in this review should be mentioned such as the language barrier, due to all evidence found was published in English, which eliminated the inclusion of available evidence published in any other language. However, it is useful to highlight that no restrictions about languages were performed; moreover, since most evidence is published in English, it is more likely that evidence meeting the eligibility criteria is published in this language.

Among the strengths of this review, we highlight that all methods were described in a protocol in advance. Moreover, a sensitive search strategy was carried out, so it is unlikely that any relevant evidence was missed. Similarly, at least two reviewers independently conducted the whole processes of selection, methodological quality assessment, and data extraction. All these processes provide reasonable confidence in our results.

\section{Conclusion}

There is lacking evidence about the benefits of some therapeutic options for unresectable oral squamous cell carcinoma. Overall, these patients can be treated using 
a multimodal approach, such as CCRT or ICT followed by CRT, which have shown good clinical outcomes. However, other therapeutic options could be considered depending on the assessment of risk/benefits, tumor extension and patient values and preferences. In all cases, any treatment should be adapted for each patient considering the clinical expertise, the available resources, and other contextual aspects.

\section{Data Sharing Statement}

All data generated or analyzed during this study are included in this published article and its supplementary information files.

\section{Author Contributions}

Conceived the study: MM and LTA. Designed the study: MM, LTA and CLA. Analyzed the data: MM, LTA, CLA. Wrote the first draft of the manuscript: MM and LTA. Contributed to the writing of the manuscript: MM, LTA, CLA. All authors made substantial contributions to conception and design, acquisition of data, or analysis and interpretation of data; took part in drafting the article or revising it critically for important intellectual content; agreed to submit to the current journal; gave final approval of the version to be published; and agreed to be accountable for all aspects of the work.

\section{Funding}

This research did not receive any specific grant from funding agencies in the public, commercial, or not-forprofit sectors.

\section{Disclosure}

The authors declare that they have no conflicts of interest for this work.

\section{References}

1. Daly B, Batchelor P, Treasure E. Introduction to the principles of public health. In: Essential Dental Public Health. Vol. 2. Oxford: Oxford University Press; 2013:1-48.

2. Siegel RL, Miller KD, Jemal A. Cancer Statistics, 2017. CA Cancer J Clin. 2017;67(1):7-30. doi:10.3322/caac.21387

3. Bray F, Ferlay J, Soerjomataram I, Siegel RL, Torre LA, Jemal A. Global cancer statistics 2018: GLOBOCAN estimates of incidence and mortality worldwide for 36 cancers in 185 countries. CA Cancer J Clin. 2018;68(6):394-424. doi:10.3322/caac.21492

4. Warnakulasuriya S. Global epidemiology of oral and oropharyngeal cancer. Oral Oncol. 2009;45(4-5):309-316. doi:10.1016/j. oraloncology.2008.06.002

5. Kyrgias G, Hajiioannou J, Tolia M, et al. Intraoperative radiation therapy (IORT) in head and neck cancer: a systematic review. Medicine (Baltimore). 2016;95(50):e5035. doi:10.1097/MD.00000000 00005035
6. Koch L, Jansen L, Brenner H, Arndt V. Fear of recurrence and disease progression in long-term ( $\geq 5$ years) cancer survivors-a systematic review of quantitative studies. Psycho-Oncol. 2013;22 (1):1-11. doi:10.1002/pon.3022

7. Dzioba A, Aalto D, Papadopoulos-Nydam G, et al. Functional and quality of life outcomes after partial glossectomy: a multi-institutional longitudinal study of the head and neck research network. J Otolaryngol Head Neck Surgery. 2017;46(1):56. doi:10.1186/s40463-017-0234-y

8. Wong T, Wiesenfeld D. Oral cancer. Aust Dent J. 2018;63(Suppl 1): S91-s99. doi:10.1111/adj.12594

9. Hartner L. Chemotherapy for oral cancer. Dent Clin North Am. 2018;62(1):87-97. doi:10.1016/j.cden.2017.08.006

10. Bulsara VM, Worthington HV, Glenny A-M, Clarkson JE, Conway DI, Macluskey M. Interventions for the treatment of oral and oropharyngeal cancers: surgical treatment. Cochrane Database Syst Rev. 2018;12(12):CD006205-CD006205.

11. Wolff KD, Follmann M, Nast A. The diagnosis and treatment of oral cavity cancer. Dtsch Arztebl Int. 2012;109(48):829-835.

12. Grégoire V, Leroy R, Heus P, et al. Oral cavity cancer: diagnosis, treatment and follow-up. Good clinical practice (GCP) Brussels: Belgian health care knowledge centre (KCE). KCE Rep. 2014:227. Available from: https://kce.fgov.be/sites/default/files/atoms/files/ KCE_227Cs_oral\%20cavity\%20cancer_Synthesis_2.pdf.

13. Alzahrani R, Obaid A, Al-Hakami H, et al. Locally advanced oral cavity cancers: what is the optimal care? Cancer Control. 2020;27 (1):1073274820920727. doi:10.1177/1073274820920727

14. Madera M, Franco J, Ballesteros M, Solà I, Urrútia G, Bonfill X. Evidence mapping and quality assessment of systematic reviews on therapeutic interventions for oral cancer. Cancer Manag Res. 2019;11:117-130. doi:10.2147/CMAR.S186700

15. Page MJ, McKenzie JE, Bossuyt PM, et al. The PRISMA 2020 statement: an updated guideline for reporting systematic reviews. BMJ. 2021;372:n71. doi:10.1136/bmj.n71

16. Ouzzani M, Hammady H, Fedorowicz Z, Elmagarmid A. Rayyan-a web and mobile app for systematic reviews. Syst Rev. 2016;5(1):210. doi:10.1186/s13643-016-0384-4

17. Moola S, Munn Z, Tufanaru C, et al. Chapter 7: systematic reviews of etiology and risk. In: Aromataris E, Munn Z, editors. JBI Manual for Evidence Synthesis. 2020. Available from: https://synthesisman ual.jbi.global. Accessed August 16, 2021.

18. Bazyka D, Vorobyov M, Kechyn I, Vorobyov O, Shmykova O. Radiothermometric personalisation of chemo- and radiotherapy for patients with advanced (III, IVa and IVb) stages malignant lesions of oral cavity, throat and epiglottis. Problemy Radiatsiinoi Medytsyny Ta Radiobiolohii. 2019;24:296-311. doi:10.33145/2304-8336-2019-24-296311

19. Biswas R, Halder A, Ghosh A, Ghosh SK. A comparative study of treatment outcome in younger and older patients with locally advanced oral cavity and oropharyngeal cancers treated by chemoradiation. South Asian j Cancer. 2019;8(1):47-51. doi:10.4103/sajc.sajc_7_18

20. Chang PM, Lu HJ, Wang LW, et al. Effectiveness of incorporating cetuximab into docetaxel/cisplatin/fluorouracil induction chemotherapy and chemoradiotherapy for inoperable squamous cell carcinoma of the oral cavity: a phase II study. Head Neck. 2017;39 (7):1333-1342. doi:10.1002/hed.24766

21. Chhatui B, Devleena RS, Maji T, Lahiri D, Biswas J. Immunomodulated anterior chemotherapy followed by concurrent chemoradiotherapy in locally advanced tongue cancer: an Institutional experience. Indian J Med Paediatr Oncol. 2015;36 (1):43-48. doi:10.4103/0971-5851.151782

22. Chitapanarux I, Traisathit P, Komolmalai N, et al. Ten-year outcome of different treatment modalities for squamous cell carcinoma of oral cavity. Asian Pacific j Cancer Prevention. 2017;18 (7):1919-1924. 
23. Donato V, Cianciulli M, Fouraki S, et al. Helical tomotherapy: an innovative radiotherapy technique for the treatment of locally advanced oropharynx and inoperable oral cavity carcinoma. Radiation Oncol. 2013;8:210. doi:10.1186/1748-717X-8-210

24. Elbers JBW, Al-Mamgani A, Paping D, et al. Definitive (chemo) radiotherapy is a curative alternative for standard of care in advanced stage squamous cell carcinoma of the oral cavity. Oral Oncol. 2017;75:163-168. doi:10.1016/j.oraloncology.2017.11.006

25. Foster CC, Melotek JM, Brisson RJ, et al. Definitive chemoradiation for locally-advanced oral cavity cancer: a 20-year experience. Oral Oncol. 2018;80:16-22. doi:10.1016/j.oraloncology.2018.03.008

26. Hayashi Y, Osawa K, Nakakaji R, et al. Prognostic factors and treatment outcomes of advanced maxillary gingival squamous cell carcinoma treated by intra-arterial infusion chemotherapy concurrent with radiotherapy. Head Neck. 2019;41(6):1777-1784. doi:10.1002/hed.25607

27. Hino S, Hamakawa H, Miyamoto Y, et al. Effects of a concurrent chemoradiotherapy with S-1 for locally advanced oral cancer. Oncol Lett. 2011;2(5):839-843.

28. Iqbal H, Jamshed A, Bhatti AB, et al. Five-year follow-up of concomitant accelerated hypofractionated radiation in advanced squamous cell carcinoma of the buccal mucosa: a retrospective cohort study. Biomed Res Int. 2015;2015:963574. doi:10.1155/2015/963574

29. Larizadeh MH, Shabani M. Survival following non surgical treatments for oral cancer: a single institutional result. Asian Pacific j Cancer Prevention. 2012;13(8):4133-4136. doi:10.7314/APJCP.2012.13.8.4133

30. Li Y, Li LJ, Wang LJ, et al. Selective intra-arterial infusion of rAd-p53 with chemotherapy for advanced oral cancer: a randomized clinical trial. BMC Med. 2014;12:16. doi:10.1186/ 1741-7015-12-16

31. Meng J, Gu QP, Meng QF, et al. Efficacy of nimotuzumab combined with docetaxel-cisplatin-fluorouracil regimen in treatment of advanced oral carcinoma. Cell Biochem Biophys. 2014;68 (1):181-184. doi:10.1007/s12013-013-9686-5

32. Murakami R, Semba A, Kawahara K, et al. Concurrent chemoradiotherapy with S-1 in patients with stage III-IV oral squamous cell carcinoma: a retrospective analysis of nodal classification based on the neck node level. Mol Clin Oncol. 2017;7(1):140-144. doi:10.3892/mco.2017.1276

33. Oyama T, Hosokawa Y, Abe K, et al. Prognostic value of quantitative FDG-PET in the prediction of survival and local recurrence for patients with advanced oral cancer treated with superselective intra-arterial chemoradiotherapy. Oncol Lett. 2020;19(6):3775-3780.

34. Patil VM, Prabhash K, Noronha V, et al. Neoadjuvant chemotherapy followed by surgery in very locally advanced technically unresectable oral cavity cancers. Oral Oncol. 2014;50(10):1000-1004. doi:10.1016/j.oraloncology.2014.07.015

35. Pederson AW, Salama JK, Witt ME, et al. Concurrent chemotherapy and intensity-modulated radiotherapy for organ preservation of locoregionally advanced oral cavity cancer. Am J Clin Oncol. 2011;34 (4):356-361. doi:10.1097/COC.0b013e3181e8420b

36. Rewadkar MS, Mahobia VK. Impact of induction chemotherapy to concurrent chemoirradiation over radiotherapy alone in advanced oral cavity. Indian J Cancer. 2017;54(1):16-19. doi:10.4103/ijc.IJC_166_17

37. Rudresha $\mathrm{AH}$, Chaudhuri $\mathrm{T}$, Lakshmaiah $\mathrm{KC}$, et al. Induction chemotherapy in technically unresectable locally advanced t4a oral cavity squamous cell cancers: experience from a regional cancer center of South India. Indian J Med Paediatr Oncol. 2017;38(4):490-494. doi:10.4103/ijmpo.ijmpo_185_16

38. Rudresha $\mathrm{AH}$, Chaudhuri $\mathrm{T}$, Lakshmaiah $\mathrm{KC}$, et al. Induction chemotherapy in locally advanced $\mathrm{T} 4 \mathrm{~b}$ oral cavity squamous cell cancers: a regional cancer center experience. Indian J Cancer. 2017;54 (1):35-38. doi:10.4103/ijc.IJC_131_17

39. Santos MA, Guinot JL, Tortajada $\overline{\mathrm{MI}}$, et al. High-dose-rate interstitial brachytherapy boost in inoperable locally advanced tongue carcinoma. Brachytherapy. 2017;16(6):1213-1218. doi:10.1016/j. brachy.2017.07.006
40. Sato K, Hayashi Y, Watanabe K, Yoshimi R, Hibi H. Concurrent chemoradiotherapy with intravenous cisplatin and docetaxel for advanced oral cancer. Nagoya J Med Sci. 2019;81(3):407-414.

41. Scher ED, Romesser PB, Chen C, et al. Definitive chemoradiation for primary oral cavity carcinoma: a single institution experience. Oral Oncol. 2015;51(7):709-715. doi:10.1016/j.oraloncology.2015.04.007

42. Shia BC, Qin L, Lin KC, et al. Outcomes for elderly patients aged 70 to 80 years or older with locally advanced oral cavity squamous cell carcinoma: a propensity score-matched, nationwide, oldest old patient-based cohort study. Cancers. 2020;12(2):258. doi:10.3390/ cancers 12020258 .

43. Singh K, Dixit A, Prashad S, Saxena T, Shahoo D, Sharma D. A randomized trial comparing radiotherapy alone versus radiotherapy with gefitinib in locally advance oral cavity cancer. Clin Cancer Investigation J. 2013;2:29-33. doi:10.4103/2278-0513.110768

44. Takácsi-Nagy Z, Oberna F, Koltai P, et al. Long-term outcomes with high-dose-rate brachytherapy for the management of base of tongue cancer. Brachytherapy. 2013;12(6):535-541. doi:10.1016/j. brachy.2013.07.001

45. Takayama K, Nakamura T, Takada A, et al. Treatment results of alternating chemoradiotherapy followed by proton beam therapy boost combined with intra-arterial infusion chemotherapy for stage III-IVB tongue cancer. J Cancer Res Clin Oncol. 2016;142 (3):659-667. doi:10.1007/s00432-015-2069-0

46. Vedasoundaram P, Raghava KA, Periasamy K, et al. The effect of high dose rate interstitial implant on early and locally advanced oral cavity cancers: update and long-term follow-up study. Cureus. 2020;12(5):e7910.

47. Wu CF, Chang KP, Huang CJ, Chen CM, Chen CY, Steve Lin CL. Continuous intra-arterial chemotherapy for downstaging locally advanced oral commissure carcinoma. Head Neck. 2014;36 (7):1027-1033. doi:10.1002/hed.23408

48. Yen CJ, Tsou HH, Hsieh CY, et al. Sequential therapy of neoadjuvant biochemotherapy with cetuximab, paclitaxel, and cisplatin followed by cetuximab-based concurrent bioradiotherapy in high-risk locally advanced oral squamous cell carcinoma: final analysis of a Phase 2 clinical trial. Head Neck. 2019;41(6):1703-1712. doi:10.1002/ hed. 25640

49. Zaidi SHM, Masood AI, Shah SIH, Hashemy I. Open label, non-randomized, interventional study to evaluate response rate after induction therapy with docetaxel and cisplatin in locally advanced squamous cell carcinoma of oral cavity. Gulf $J$ Oncol. 2020;1 (32):12-28.

50. Zhang H, Dziegielewski PT, Biron VL, et al. Survival outcomes of patients with advanced oral cavity squamous cell carcinoma treated with multimodal therapy: a multi-institutional analysis. J Otolaryngol. 2013;42(1):30. doi:10.1186/1916-0216-42-30

51. Müller-Richter U, Betz C, Hartmann S, Brands RC. Nutrition management for head and neck cancer patients improves clinical outcome and survival. Nutr Res. 2017;48:1-8. doi:10.1016/j.nutres.2017.08.007

52. Tomar SL, Loree M, Logan H. Racial differences in oral and pharyngeal cancer treatment and survival in Florida. Cancer Causes Control. 2004;15 (6):601-609. doi:10.1023/B:CACO.0000036166.21056.f9

53. Zakeri K, MacEwan I, Vazirnia A, et al. Race and competing mortality in advanced head and neck cancer. Oral Oncol. 2014;50 (1):40-44. doi:10.1016/j.oraloncology.2013.09.012

54. Shanti RM, O'Malley BW Jr. Surgical management of oral cancer. Dent Clin North Am. 2018;62(1):77-86. doi:10.1016/j. cden.2017.08.005

55. Zanoni DK, Montero PH, Migliacci JC, et al. Survival outcomes after treatment of cancer of the oral cavity (1985-2015). Oral Oncol. 2019;90:115-121. doi:10.1016/j.oraloncology.2019.02.001

56. Sylvester RJ, Canfield SE, Lam TB, et al. Conflict of evidence: resolving discrepancies when findings from randomized controlled trials and meta-analyses disagree. Eur Urol. 2017;71(5):811-819. doi:10.1016/j.eururo.2016.11.023 
57. Alonso-Coello P, Schunemann HJ, Moberg J, et al. GRADE evidence to decision (EtD) frameworks: a systematic and transparent approach to making well informed healthcare choices. 1: introduction. $B M J$. 2016;353:i2016. doi:10.1136/bmj.i2016

58. Sun W, Shi Q, Zhang H, et al. Advances in the techniques and methodologies of cancer gene therapy. Discov Med. 2019;27 (146):45-55.
59. Farmer ZL, Kim ES, Carrizosa DR. Gene therapy in head and neck cancer. Oral Maxillofac Surg Clin North Am. 2019;31(1):117-124. doi:10.1016/j.coms.2018.08.006

60. Perrotti V, Caponio VCA, Mascitti M, et al. Therapeutic potential of antibody-drug conjugate-based therapy in head and neck cancer: a systematic review. Cancers. 2021;13:13. doi:10.3390/cancers13133126

\section{Publish your work in this journal}

Cancer Management and Research is an international, peer-reviewed open access journal focusing on cancer research and the optimal use of preventative and integrated treatment interventions to achieve improved outcomes, enhanced survival and quality of life for the cancer patient.
The manuscript management system is completely online and includes a very quick and fair peer-review system, which is all easy to use. Visit http://www.dovepress.com/testimonials.php to read real quotes from published authors. 